\title{
Using data from over 72,000 individuals to model age-specific increase in service demand from the 2019 modification to NICE criteria for cochlear implantation.
}

\author{
Rob Low ${ }^{1}$ and Mahmood Bhutta ${ }^{2}$ \\ ${ }^{1}$ Royal Sussex County Hospital \\ ${ }^{2}$ Brighton and Sussex University Hospitals NHS Trust
}

November 27, 2020

\begin{abstract}
* The UK National Institute for Health and Care Excellence has estimated a $70 \%$ increase in demand resulting from the 2019 modification to cochlear implant criteria * We modelled the projected increase using our large database of pure tone audiometry results, and adjusted for frailty as a marker of risk of general anaesthesia * Our results suggest an overall $79 \%$ increase in demand, with most of this for adult implantation, and in particular for those over the age of $65 *$ Our findings are important for those planning delivery of cochlear implant services
\end{abstract}

\section{Hosted file}

CI referrals increase after NICE 2019 criteria-Body Text.pdf available at https://authorea. com/users/379440/articles/495643-using-data-from-over-72-000-individuals-to-model-agespecific-increase-in-service-demand-from-the-2019-modification-to-nice-criteria-forcochlear-implantation 